\title{
Dietary Habits of an Ambulatory Diabetic Population at the University Hospital of Conakry, Guinea
}

\author{
Mamadou Mansour Diallo1*, Alpha Mamadou Diallo', Jules Comlan Gninkoun², Amadou Kaké1, \\ Mamadou Chérif Diallo1, Thierno Amadou Wann³, Djénabou Diallo3 , Kadiatou Diallo3,

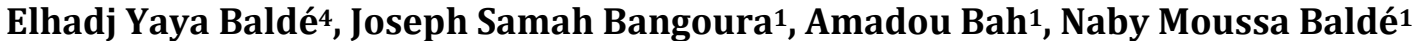

\begin{abstract}
${ }^{1}$ Service d'Endocrinologie, Diabétologie et Maladies Métaboliques, Centre Hospitalier Universitaire de Conakry, Conakry, Guinée ${ }^{2}$ Service d'Endocrinologie, Diabétologie, Centre National Hospitalier Universitaire (CNHU) de Cotonou, Cotonou, Bénin ${ }^{3}$ Service de Médecine Interne, Centre Hospitalier Universitaire de Conakry, Conakry, Guinée ${ }^{4}$ Service de Cardiologie, Centre Hospitalier Universitaire de Conakry, Conakry, Guinée Email: *m.mansour02@yahoo.fr
\end{abstract}

How to cite this paper: Diallo, M.M., Diallo, A.M., Gninkoun, J.C., Kaké, A., Diallo, M.C., Wann, T.A., Diallo, D., Diallo, K., Baldé, E.Y., Bangoura, J.S., Bah, A. and Baldé, N.M. (2021) Dietary Habits of an Ambulatory Diabetic Population at the University Hospital of Conakry, Guinea. Open Journal of Endocrine and Metabolic Diseases, 11, 129-135.

https://doi.org/10.4236/ojemd.2021.116010

Received: April 6, 2021

Accepted: June 21, 2021

Published: June 24, 2021

Copyright (c) 2021 by author(s) and Scientific Research Publishing Inc. This work is licensed under the Creative Commons Attribution International License (CC BY 4.0).

http://creativecommons.org/licenses/by/4.0/ (c) (i) Open Access

\begin{abstract}
Background: A healthy diet is essential for optimal diabetes management. However, dietary habits vary from one region to another, making it challenging to standardize practices. Objective: To describe the diet habits of patients living with diabetes in Guinea. Methods: We conducted a dietary habits survey among 102 patients living with diabetes followed-up at the University Hospital of Conakry in Guinea between January and March 2012. Data were collected by individual interview on the basis of a three-item questionnaire: diabetes data, diet mode, and food composition. Results: In total, $85 \%$ of patients were consuming 3 meals daily; $13.7 \%$ had a collation and $25 \%$ had snacking habits. The meal was individual in $82.4 \%$ and collective in $17.6 \%$ of patients. The main foods consumed daily were: rice (93.1\%), fish (93.1\%), palm oil (91.1\%), bread (87.2\%). Foods consumed regularly (2 to 3 times a week) were: meat (49\%), eggs (23.5\%), dairy products (34.3\%), fruit (43.1\%), vegetables (40.2\%) and peanut oil (21.5\%). The food bans reported were: regular sugar (100\%), sodas (62.7\%), peanuts $(84.3 \%)$ and sweetened fruits (55.8\%). Conclusion: Combining dietary recommendations and dietary habits is essential for appropriate management of diabetic patients. The assessment of local food glycemic indexes and the training of dietitians remains a challenge in our context.
\end{abstract}

\section{Keywords}

Diet, Habits, Diabetes, Guinea 


\section{Introduction}

Diabetes is a chronic disease whose prevalence is constantly increasing in the world in general and in developing countries in particular. In Guinea, its prevalence has been estimated at $6.7 \%$ corresponding to about 700,000 people with diabetes [1]. Diabetes management is mainly aimed at preventing long-term complications and improving the quality of life of patients. All the diabetes management guidelines proposed by scientific societies recommend lifestyle interventions combined with drug treatments [2]. Although the therapeutic arsenal is improving dramatically, lifestyle measures remain essential to diabetes management. Indeed, a balanced diet with an appropriate distribution of meal times and nutritional composition can improve the metabolic balance of patients living with diabetes [3]. Key nutrients such as proteins, carbohydrates, lipids and micro-nutrients are available in a wide variety of foods. However, dietary habits vary widely from one population to another. These habits are largely influenced by geographical region, culture and socio-economic level [4]. The diet of the diabetic patient is a subject of debate and controversy between dietary recommendations and eating habits.

In Africa, the weight of customs and representations, poverty and the virtual absence of specialised training in dietetics are potential obstacles to a balanced diet adapted to patients living with diabetes. The available data generally raise questions related to the glycaemic indexes of local foods [5], the diversification and quantification of food portions [6]. In Western countries, the diet of patients living with diabetes is generally supported by dietary management. Thus, the composition of the different meals is assessed both qualitatively and quantitatively. On the other hand, in Africa, very few patients benefit from specialised care due to a lack of dieticians. Moreover, the meal is often taken in a group around a common bowl. In this context, the qualitative and quantitative evaluation of the different categories of food consumed remains delicate. In Africa, studies on the diet of people with diabetes remain rare and in Guinea, to our knowledge, there is no data on the dietary practices of patients living with diabetes.

The objective of this work was to describe the dietary habits of a population of patients living with diabetes followed-up on an outpatient basis at the University Hospital of Conakry, Guinea.

\section{Methods}

\subsection{Type of Study}

This was a descriptive cross-sectional study of 102 patients living with diabetes followed-up on an outpatient basis at the Conakry University Hospital (CHU) in Conakry (Guinea). A dietary survey was carried out between January and March 2012.

Patients with diabetes followed-up on ambulatory care basis were selected consecutively during the study period. 


\subsection{Variables and Data Collection}

A questionnaire divided into four sections was administered:

1) Clinical and epidemiological data: age, gender, residence, type of diabetes, duration of diabetes, glycemic control (defined by the glycated hemoglobin value in \%), body mass index (measured by mechanic scale and defined by weight divided by height square), waist circumference (using tape measure) and blood pressure (systolic and diastolic blood pressures measured by Sphygmomanometer);

2) Diet habits: the mode of feeding defined by the number of daily meals, whether or not collations were taken, whether or not snacks were eaten, and whether or not the food was eaten in a common or individual dish;

3) The dietary composition of meals: the composition of the meals was determined by the type and frequency of food consumed;

4) Food prohibitions: determined by the collection of the different foods considered prohibited by the patients.

The data were collected consecutively during the outpatient consultation with the collection of clinical and biological parameters and direct administration of the standard questionnaire.

\subsection{Statistical Analysis}

Data were entered and analyzed in Epi Info software version 3.3.5. Quantitative variables were expressed as means and standard deviations while categorical variables were expressed as absolute values and percentages.

\section{Results}

Sociodemographic and clinical characteristics of the study population are summarized in Table 1 . The mean age of the patients was $49 \pm 15(17-80)$ years, divided into 88 with type 2 diabetes (86\%), 13 with type 1 diabetes (13\%) and 1 secondary diabetes. The sex ratio $(\mathrm{H} / \mathrm{F})$ was 0.75 and the mean body mass index (BMI) was $28.22 \pm 6(19-42) \mathrm{kg} / \mathrm{m}^{2}$. A total of 94 patients $(92.2 \%)$ of the study population lived in urban areas compared to 8 patients $(7.8 \%)$ who lived in rural areas. The average waist circumference was $88 \pm 9(65-115) \mathrm{cm}$ in men and $86 \pm 12(72-140) \mathrm{cm}$ in women. The systolic blood pressure (SBP) was $133 \pm 20(80-190) \mathrm{mmHg}$ and the diastolic blood pressure (DBP) was $82.94 \pm 10.85(60-118) \mathrm{mmHg}$.

The duration of diabetes was $4.77 \pm 3.6(0-16)$ years and the mean HbAlc of was $8.95 \pm 2.06(5.3 \%-14 \%)$.

The most common mode of diet was the consumption of three meals a day and in an individual dish. Details are presented in Table 2. The most common food categories were: rice (99\%), fish (100\%), palm oil (100\%) and bread (97\%); data presented in Table 3 . With regards to the frequency of consumption of the different foods, were consumed at daily basis: rice (93.1\%), fish (93.1\%), palm oil (91.1\%) and bread (87.2\%. Meat, Fruits, Vegetables, and Dairy were consumed 2 to 3 times a week in $49 \%, 43 \%, 40 \%$, and $34.5 \%$, respectively (Table 4 ). The most reported food bans were ordinary sugar (100\%), peanuts $(84.3 \%)$, and sodas $(62.7 \%)$ as presented in are presented in Table 5. 
Table 1. Sociodeographic and clinical characteristics of patients.

\begin{tabular}{cc}
\hline Characteristics & Mean \pm SD/N (\%) \\
\hline Age (years), mean \pm SD & $49 \pm 15$ \\
Female (versus male), n (\%) & $58(56.8)$ \\
Diabetes duration (years), mean \pm SD & $4.77 \pm 3.6$ \\
HbAlc (\%), mean \pm SD & $8.95 \pm 2.06$ \\
Urban residence (versus rural) & $94(92.2)$ \\
BMI & $28 \pm 6$ \\
Systolic blood pressure (mmHg), mean \pm SD & $133 \pm 20$ \\
Diastolic blood pressure (mmHg), mean \pm SD & $82.94 \pm 10.85$ \\
\hline
\end{tabular}

Table 2. Description of patients according to their mode of feeding.

\begin{tabular}{cc}
\hline Characteristics & $\mathrm{N}(\%)$ \\
\hline Number of daily meals $(\mathbf{n}=102)$ & $87(85)$ \\
3 meals & $14(14)$ \\
Less than 3 meals & $1(1)$ \\
More than 3 meals & \\
Collation intake $(\mathbf{n}=13)$ & $(1.96)$ \\
2 collations & $11(10.78)$ \\
1 collation & $89(87.21)$ \\
No collation & \\
Skipped meals $(\mathbf{n}=14)$ & $9(64.28)$ \\
Breakfast & $2(14.28)$ \\
Lunch & $3(21.4)$ \\
Diner & \\
Nibbling on food $(\mathbf{n}=102)$ & $25(24.5)$ \\
Yes & $77(75.5)$ \\
No & \\
Eating mode $(\mathbf{n}=102)$ & $84(84.41)$ \\
Individual meal & $18(17.6)$ \\
Shared meal &
\end{tabular}

\section{Discussion}

This work is part of an exploratory framework of the diet of patients living with diabetes in Guinea. Indeed, apart from preliminary work on the glycemic index of fonio carried out in 2008 at Conakry University Hospital by Baldé et al. [5], there is no data on the dietary practices of patients living with diabetes in Guinea. The regular consumption of three daily meals found in the majority of patients in our study was reported by Besançon et al. in Mali [7] and Nthangeni et al. in South Africa [8]. However, it is worth mentioning the large number of skipped meals found in this work, particularly the breakfast. In their study, Nthangeni et al. [8] also reported skipping meals, mainly for breakfast. The deleterious effect of skipped meals on metabolic balance is well known both in the general population and in patients living with diabetes. Meal skipping is described 
Table 3. Description of patients according to the categories of food consumed.

\begin{tabular}{cc}
\hline Characteristics & $\mathrm{N}(\%)$ \\
\hline Carbohydrates & $101(99)$ \\
Rice & $97(95.1)$ \\
Bread & $96(67.6)$ \\
Fonio & $33(32.7)$ \\
Cassava & \\
Protéines & $102(100)$ \\
Fish & $80(78.4)$ \\
Meat & $39(38.6)$ \\
Eggs & \\
Lipids & $102(100)$ \\
Red oil & $65(63.71)$ \\
Cheese & $40(39.2)$ \\
Peanut oil & $18(17.6)$ \\
Butter & $4(3.9)$ \\
Olive oil & \\
Dairy products & $63(61.8)$ \\
Yes & $39(38.2)$ \\
No & $69(67.6)$ \\
& \\
Fegetables & \\
Fruits and Vegetables & \\
Fruits & \\
\hline
\end{tabular}

Table 4. Frequency of consumption of different types of food reported by patients.

\begin{tabular}{cc}
\hline Characteristics & $\mathrm{N}(\%)$ \\
Daily & $95(93.1)$ \\
Rice & $95(93.1)$ \\
Fish & $93(91.1)$ \\
Palm oil & $89(87.2)$ \\
Bread & $31(30.30)$ \\
Cheese & \\
& \\
Two to three times a week & $50(49)$ \\
Meat & $44(43.1)$ \\
Fruits & $41(40.2)$ \\
Vegetables & $35(34.5)$ \\
Dairy products & $24(23.5)$ \\
Eggs & $22(21.5)$ \\
Peanut oil &
\end{tabular}

Table 5. Foods reported as prohibited by patients.

\begin{tabular}{cc}
\hline Characteristics & N (\%) \\
\hline Ordinary sugar & $102(100)$ \\
Peanuts & $86(84.3)$ \\
Sodas & $64(62.7)$ \\
Sweet fruits & $57(55.8)$ \\
Alcohol & $5(4.9)$ \\
\hline
\end{tabular}


as a factor promoting snacking on the one hand and activation of the neoglucogenesis pathways on the other, leading to glycemic imbalance and weight gain [9]. The low frequency of snacking reported in this study is consistent with nutritional habits in our regions where snacking is not common. Contrary to popular belief, eating from a common bowl was marginal in this study. Indeed, several authors had reported the negative influence of eating from a common bowl for patients living with diabetes due to the impossibility of prescribing them a specific diet in this context. However, the finding in our study could be explained by a change in the dietary practices of patients living with diabetes in Africa. It should also be noted that these were people living mainly in urban areas in Conakry who had benefited from therapeutic education that encouraged them to control their food intake and to take an individual meal. Indeed, eating in an individual dish make it easier to control the amount of calories consumed. The different foods reported in this study cover most of the nutritional needs essential to a balanced diet for patients living with diabetes. Indeed, a regular consumption of low carbohydrates, proteins and lipids was found in the majority of patients. The consumption of carbohydrates in the form of rice, fonio and cassava in our study was close to that found in Mali with rice and fonio, while Nthangeni et al. reported maize, sorghum and bread in South Africa [7] [8]. The fish found to be the main protein consumed is thought to be due to the coastal location of the city of Conakry, with its important artisanal and industrial fishing activity. Palm oil produced locally in Guinea is a highly prized part of the daily diet, which would explain why it is found in all the patients interviewed. The high content of saturated fatty acids in palm oil is described, which makes it advisable to recommend its moderate consumption, especially for patients living with diabetes [10]. Unsaturated oils, which are rich in omega 3, seem to be little consumed because of their high cost. The notions on food bans reported in this study are consistent with the usual educational approaches concerning the diet of patients living with diabetes.

This study has some limits to mention. First, we didn't use standardized nutritional questionnaire as these are not validated in our context yet rendering impossible to calculate nutritional scores. Also, amount of calories are not evaluated. Studies evaluating the glycemic index of different local foods as well as the caloric quantification of food portions are necessary to improve the dietary and nutritional management of diabetic patients in Guinea.

\section{Conclusion}

This study on the dietary habits of patients living with diabetes in Guinea shows a varied consumption of food, covering the main food groups. However, the evaluation of the energy value of meals and the composition of standard meals are essential for adequate dietary management of patients. Combining dietary recommendations and eating habits is a challenge for the appropriate management of patients living with diabetes in our context. This involves evaluating the 
glycemic indexes of the various local foods and training dietitians.

\section{Conflicts of Interest}

The authors do not declare any conflict of interest.

\section{References}

[1] Baldé, N.M., Diallo, I., Baldé, M.D., et al. (2007) Diabetes and Impaired Fasting Glucose in a Rural and Urban Populations in Futa Jallon (Guinea): Prevalence and Associated Risk Factors. Diabetes \& Metabolism, 33, 114-120. https://doi.org/10.1016/j.diabet.2006.10.001

[2] American Diabetes Association, Position Statement (2013) Standards of Medical Care in Diabetes-2013. Diabetes Care, 36, S11-S66.

https://doi.org/10.2337/dc13-S011

[3] Lesourd, B.M., Mazari, L. and Ferry, M. (1998) The Role of Nutrition in Immunity in the Aged. Nutrition Reviews, 56, S113-S125. https://doi.org/10.1111/j.1753-4887.1998.tb01628.x

[4] Yonkeu, S., Maïga, A.H., Mampouya, M., et al. (2003) Conditions socio-économiques des populations et risques de maladies: Le bassin versant du barrage de Yitenga au Burkina Faso. La revue électronique en sciences de l'environnement, 4, 1-15. http://vertigo.revues.org/4778 https://doi.org/10.4000/vertigo.4778

[5] Balde, N.M., Besançon, S. and Sidibé, T.A. (2008) Index glycémique du fonio (digitaria exilis), interêt dans l'alimentation des sujets diabétiques en Afrique de l'Ouest. Diabetes \& Metabolism, 34, H93. https://doi.org/10.1016/S1262-3636(08)73103-3

[6] Barou, J. and Moniel, V. (1997) Alimentation et rôles familiaux, La cuisine familiale des immigrés africains. Ethnologie Française, 27, 96-102.

[7] Besançon, S., Sidibé, A.T. and Nientao, I. (2009) Le diabète au Mali: Aspects diététiques. Développement et Santé, 193, 1-7.

[8] Nthangeni, G., Steyn, N., Alberts, M., Steyn, K., Levitt, N., Laubscher, R. and Temple., N. (2002) Dietary Intake and Barriers to Dietary Compliance in Black Type 2 Diabetic Patients Attending Primary Health-Care Services. Public Health Nutrition, 5, 329-338. https://doi.org/10.1079/PHN2002256

[9] Ouassila, S. (2012) Pratiques alimentaires des diabétiques. Étude de quelques cas à Oran (Algérie). Économie Rurale, 318-319, 80-95.

http://economierurale.revues.org/2816

[10] ANSES (2011) Actualisation des apports nutritionnels conseillés pour les acides gras. Rapport d'expertise collective. ANSES, Maisons-Alfort, France,323 p. https://www.anses.fr/en/system/files/NUT2006sa0359Ra.pdf 